\title{
A REMESSA NECESSÁRIA NO NCPC E OS EFEITOS NO PROCESSO TRIBUTÁRIO
}

\author{
Morvan Meirelles
}

\section{INTRODUÇÃO}

O reexame necessário do direito processual brasileiro tem raízes históricas no direito penal português da era medieval, então instituído por intermédio de lei de 1355. Entre nós, surgiu no período imperial, incialmente previsto no art. 90 da Lei de 4 de outubro de 1831 (sem número), sob a denominação "apellação ex-officio", estando presente desde então em nossas codificações processuais, marcadamente na de 1939, também sob a denominação "apelação ex-officio" (art. 822 do Decreto-Lei n. 1.608), e na de 1973 (art. 475 da Lei n. 5.869). A justificativa para a existência do instituto, desde sua previsão inicial em nosso ordenamento jurídico, sempre se calcou nas supostas fragilidade e desorganização dos órgãos incumbidos de defender em juízo os entes públicos, servindo, portanto, de instrumento de garantia do interesse coletivo.

Quando da elaboração do anteprojeto do Código de Processo Civil de 1973 (CPC/73), superada a discussão quanto à sua natureza jurídica, ${ }^{1}$ diversos doutrinadores, dentre eles Alfredo Buzaid e Ada Pellegrino Grinover, entenderam pela necessária abolição do instituto de nossa codificação processual, apontando

1 Já na época, como hoje, a doutrina entendia em uníssono que o reexame necessário, ou "remessa necessária", não tem natureza de recurso, mas de mera condição de eficácia da sentença proferida contra a Fazenda Pública. 
ser este desnecessário e inútil, uma vez que não seria papel do judiciário corrigir prováveis deficiências dos representantes da Fazenda Pública em juízo e que a desídia desses agentes deveria ser impedida e controlada mediante outros mecanismos mais eficazes, ${ }^{2}$ ou até mesmo inconstitucional, uma vez que, ao condicionar a eficácia de uma sentença à posição de um dos partícipes do processo, se estaria ferindo gravemente o princípio da isonomia processual. ${ }^{3}$

Nesse particular, saliente-se que atualmente as críticas ao instituto têm como raiz o mesmo questionamento quanto a sua necessidade e sua utilidade, entretanto sob o enfoque de que aqueles órgãos de defesa judicial de entes públicos já se encontram bem organizados, aparelhados com profissionais altamente qualificados e preparados para o exercício, a contento, de sua defesa em juízo. Destaque-se, ainda, a justificada dúvida quanto à efetividade da mera reapreciação, pela segunda instância, de matéria objeto de sentença sujeita ao duplo grau de jurisdição sem peça argumentativa que indique as razões para sua alteração. E, nessa perspectiva, o prolongamento do processo pode dirigir-se contra os anseios da sociedade, em vista da esperada celeridade na solução das demandas sujeitas à apreciação do poder judiciário.

Em função do peso da atuação daqueles entes públicos em juízo, essas críticas ao instituto ecoam com mais intensidade nos dias de hoje. Com efeito, segundo Rogério Mollica, “o Poder Público é o responsável por grande parte das ações que tramitam hoje no Judiciário", respondendo por mais de $70 \%$ dos casos em tramitação nos tribunais superiores. Nessa seara, inobstante e ainda assim incluído no NCPC sob a denominação "remessa necessária" (art. 496), o instituto sofreu maiores limitações, sendo oportuna sua análise à luz do processo tributário.

\section{A REMESSA NECESSÁRIA NO NCPC}

$\mathrm{Na}$ remessa necessária, observadas as restrições previstas em lei, sujeitam-se as decisões de mérito proferidas contra a União, os estados, o Distrito Federal, os

2 BUZAID, Alfredo. Da apelação "ex officio" no sistema do Código do Processo Civil. São Paulo: Saraiva, 1951.

3 GRINOVER, Ada Pellegrini. Os princípios constitucionais e o Código de Processo Civil. São Paulo: Bushatsky, 1975.

4 MOLLICA, Rogério. A remessa necessária e o Novo Código de Processo Civil. In: DIDIER JR. Fredie et al. (Coord.). Processo nos tribunais e meios de impugnação às decisões judiciais. São Paulo: Juspodivm, 2016. p. 101. 
municípios e suas respectivas autarquias e fundações de direito público, bem como aquelas que julgarem procedentes, no todo ou em parte, os embargos à execução fiscal, a reexame compulsório pelo tribunal ad quem, ainda que não tempestiva e voluntariamente impugnadas pelo representante em juízo daqueles entes públicos.

Com o advento do NCPC, destacam-se como inovações do instituto as limitações à sua aplicação, as quais podem ser quantitativas, elencadas nos incisos I a III do $₫ 3^{\circ}$ do art. 496 , e qualitativas, conforme os incisos I a IV do $\ 4^{\circ}$. Nesse sentido, em relação às primeiras, não estão sujeitas ao duplo grau de jurisdição obrigatório as sentenças em que a Fazenda Pública for condenada ou que representem proveito econômico obtido na causa em valor certo e líquido inferior a 1.000 salários-mínimos para a União Federal e suas respectivas autarquias e fundações, 500 salários-mínimos para os estados, o Distrito Federal e os municípios capitais de estados, e 100 salários mínimos para os demais municípios e suas respectivas autarquias e fundações. ${ }^{5}$ Quanto às segundas, não estão sujeitas ao duplo grau de jurisdição obrigatório as sentenças fundadas em súmula de tribunal superior, acórdão proferido pelo Superior Tribunal de Justiça (STJ) e pelo Supremo Tribunal Federal (STF) em julgamento de recursos repetitivos, entendimento firmado em incidente de resolução de demandas repetitivas ou de assunção de competência, ou entendimento coincidente com orientação vinculante firmada no âmbito administrativo do próprio ente público, consolidada em manifestação, parecer ou súmula administrativa.

É interessante notar que o legislador procurou adequar os limites quantitativos de aplicação do instituto às supostas restrições organizativas e estruturais próprias da representação judicial de cada ente público considerado, conforme sua capacidade econômica. Entretanto, como bem ressalvado por Rogério Mollica, ${ }^{6}{ }^{\text {como }}$ todo critério objetivo, este

não vai ser sempre justo, pois existem municípios que não são capitais de Estados que possuem população, estrutura e arrecadação muito superior a capitais ou mesmo Estados. Vejam-se os casos dos municípios Paulistas

5 Desde março de 2002, com a entrada em vigor do art. $1^{\circ}$ da Lei n. 10.352/2001, o citado art. 475 do $\mathrm{CPC} / 73$ passou a vigorar com uma limitação quantitativa em mesmos moldes, entretanto em valor muito menor e uniformemente considerada, equivalente a 60 salários-mínimos vigentes.

6 MOLLICA, Rogério. A remessa necessária e o Novo Código de Processo Civil. In: DIDIER JR., Fredie et al. (Coord.). Processo nos tribunais e meios de impugnação às decisões judiciais. São Paulo: Juspodivm, 2016. p. 104. 
de Guarulhos e Campinas, que possuem população superior a um milhão de habitantes, população essa superior a de Estados como Acre, Amapá e Roraima.

Saliente-se, outrossim, que o próprio aumento dos valores de alçada para fins de aplicação do instituto acaba por corroborar o argumento em prol de sua inutilidade, especialmente à luz da atual realidade processual brasileira.

Com efeito, a título de exemplo, não parece crível que a Procuradoria-Geral da Fazenda Nacional (PGFN) possa se abster de interpor recurso voluntário em causa que sujeite a Fazenda Pública a condenação superior a 1.000 salários-mínimos. Mais que isso, no âmbito do processo tributário, especificamente para as execuções fiscais movidas pela União Federal por intermédio daquela mesma PGFN, com o advento do art. 20 da Portaria PGFN n. 396/2016, é difícil imaginar que o procurador responsável, concentrando esforços em ações executivas que representem créditos fiscais de mais de $\mathrm{R} \$ 1$ milhão, possa se furtar de interpor recurso contra os embargos à execução que infirmam a certeza e/ou a iliquidez daqueles títulos, uma vez que julgados procedentes.

Por outro lado, é digna de nota a sensibilidade do legislador em estender as hipóteses de limitação qualitativa de aplicação do instituto, em homenagem ao princípio da economia processual e em preocupação, ainda que paradoxal, à célere resolução das demandas sujeitas à apreciação do poder judiciário. Nesse passo, cite-se especialmente as sentenças proferidas com fulcro em entendimento coincidente com orientação vinculante firmada no âmbito administrativo do próprio ente público. Novamente fazendo um paralelo com o processo tributário, realmente não faria sentido um procurador estar dispensado de recorrer a uma tese

7 “Art. 20. Serão suspensas, nos termos do art. 40, caput, da Lei $n^{\circ} 6.830$, de 1980, as execuções fiscais cujo valor consolidado seja igual ou inferior a um milhão de reais, desde que não conste nos autos garantia útil à satisfação, integral ou parcial, do crédito executado. $\S 1^{\circ}$ Entende-se por garantia inútil aquela de difícil alienação, sem valor comercial ou irrisória. $\S 2^{\circ} \mathrm{O}$ Procurador da Fazenda Nacional não requererá a suspensão de que trata o caput enquanto pendente causa de suspensão da exigibilidade do crédito, julgamento de exceção de pré-executividade, embargos ou outra ação ou recurso que infirme a certeza e liquidez do crédito e obste o prosseguimento, ainda que provisório, da cobrança judicial. § $3^{\circ} \mathrm{O}$ disposto neste artigo não se aplica às execuções movidas contra pessoas jurídicas de direito público, às execuções movidas para cobrança da Dívida Ativa do FGTS, bem como às execuções nas quais constem, nos autos, informações de falência ou recuperação judicial da pessoa jurídica devedora." 
tributária e, ainda assim, os autos serem remetidos ao tribunal ad quem para a reapreciação de matéria que a própria Fazenda Pública reconhece como sucumbente. Ressalte-se, por fim, que a teor de jurisprudência pacífica do STJ em análise de limitação quantitativa à aplicação do instituto, conforme imposta pelo art. $1^{\mathrm{o}}$ da Lei n. 10.352/2001, ${ }^{8}$ bem como em função da redação do art. 14 da Lei n. 12.016/2009, ${ }^{9}$ essas limitações não se aplicariam ao reexame necessário de sentenças proferidas em mandado de segurança. ${ }^{10}$

8 "Art. $1^{\circ}$ Os artigos da Lei $n^{\circ}$ 5.869, de 11 de janeiro de 1973, que instituiu o Código de Processo Civil, a seguir mencionados, passam a vigorar com as seguintes alterações: 'Art. 475. Está sujeita ao duplo grau de jurisdição, não produzindo efeito senão depois de confirmada pelo tribunal, a sentença: I - proferida contra a União, o Estado, o Distrito Federal, o Município, e as respectivas autarquias e fundações de direito público; II - que julgar procedentes, no todo ou em parte, os embargos à execução de divida ativa da Fazenda Pública (art. 585, VI). $\S 1^{\circ}$ Nos casos previstos neste artigo, o juiz ordenará a remessa dos autos ao tribunal, haja ou não apelação; não o fazendo, deverá o presidente do tribunal avocá-los. $\S 2^{\circ}$ Não se aplica o disposto neste artigo sempre que a condenação, ou o direito controvertido, for de valor certo não excedente a 60 (sessenta) salários mínimos, bem como no caso de procedência dos embargos do devedor na execução de dívida ativa do mesmo valor. § $3^{\circ}$ Também não se aplica o disposto neste artigo quando a sentença estiver fundada em jurisprudência do plenário do Supremo Tribunal Federal ou em súmula deste Tribunal ou do tribunal superior competente' (NR) [...]."

9 "Art. 14. Da sentença, denegando ou concedendo o mandado, cabe apelação. § $1^{\circ}$ Concedida a segurança, a sentença estará sujeita obrigatoriamente ao duplo grau de jurisdição. $\S 2^{\circ}$ Estende-se à autoridade coatora o direito de recorrer. $\S 3^{\circ} \mathrm{A}$ sentença que conceder o mandado de segurança pode ser executada provisoriamente, salvo nos casos em que for vedada a concessão da medida liminar. $\S 4^{\circ} \mathrm{O}$ pagamento de vencimentos e vantagens pecuniárias assegurados em sentença concessiva de mandado de segurança a servidor público da administração direta ou autárquica federal, estadual e municipal somente será efetuado relativamente às prestações que se vencerem a contar da data do ajuizamento da inicial."

10 A não aplicação das limitações ao Mandado de Segurança é alvo de crítica por parte de Leonardo José Carneiro da Cunha: "Muito embora prevaleça no STJ o entendimento contrário, parece mais adequado entender que as hipóteses de dispensa de remessa necessária também se aplicam ao mandado de segurança, com a ressalva das situações previstas no $\S 3^{\circ}$ do art. 496 do CPC para os casos em que não há sentença líquida ou não se tem como aferir o valor do direito discutido. Se, numa demanda submetida ao procedimento comum, não há remessa necessária naquelas hipóteses, por que haveria num mandado de segurança? Ora, sabe-se que a única diferença entre uma demanda de rito comum e o mandado de segurança está na restrição probatória deste último, que se revela cabivel apenas quando os fatos estiverem provados por documentos, de forma pré-constituída. Para que se mantenha unidade no sistema, é preciso, então, que se entenda que aquelas hipóteses de dispensa de reexame necessário alcancem também a sentença proferida no mandado de segurança. Não atende ao princípio da razoabilidade deixar de estender as 


\section{QUESTÕES ENVOLVENDO A REDAÇÃO DO ART. 496 DO NCPC}

Antes de representar crítica vazia à técnica legislativa no Brasil, cabe investigar as dificuldades advindas da redação do citado dispositivo de lei.

Como primeiro destaque, atente-se para a redação do $\int 1^{\circ}$ do art. 496 do NCPC. Inspirado no $\int 1^{\circ}$ do art. 475 do CPC/73, o novo dispositivo determina que caberá ao juiz ordenar a remessa dos autos ao tribunal somente quando não for interposta apelação. ${ }^{11}$ Ocorre que o procurador poderá optar por apelar de um só capítulo da sentença, sendo que, em contraponto, a teor da Súmula 325 do STJ, "a remessa oficial devolve ao Tribunal o reexame de todas as parceladas da condenação suportadas pela Fazenda Pública, inclusive dos honorários de advogado”.

Nesse sentido, de modo a evitar preclusão de ponto da sentença que não seja objeto de recurso voluntário, caberá ao procurador responsável, observados os limites quantitativos e qualitativos estabelecidos no próprio artigo de lei, simplesmente valer-se do instituto da remessa necessária, confiando, portanto, no

hipóteses de dispensa do reexame necessário ao mandado de segurança. Demais disso, a previsão constitucional do mandado de segurança, ao fixar como requisito de sua admissibilidade o direito líquido e certo, pressupõe e exige um procedimento célere e expedido para o controle dos atos públicos. Dai por que se afina com a envergadura constitucional do mandado de segurança entender que os $\S \S 3^{\circ}$ e $4^{\circ}$ do art. 496 do CPC a eles se aplicam, de sorte que, naqueles casos, não há reexame necessário" (CUNHA, Leonardo José Carneiro da. In: WAMBIER, Teresa Arruda Alvim et al. (Coord.). Breves comentários ao Novo Código de Processo Civil. São Paulo: Revista dos Tribunais, 2015. p. 1262).

11 Apesar de não explicitamente delimitado, aqui entendida como apelação pela Fazenda Pública. Nesse sentido, cite-se Daniel Amorim Assumpção Neves: "Como o art. 496, $\S 1^{\circ}$, do Novo CPC afirma apenas que a não interposição de apelação dentro do prazo leva à remessa necessária, sem especificar de qual das partes é a apelação não interposta, é possivel concluir que, havendo sucumbência reciproca e sendo interposta apelação pela parte contrária à Fazenda Pública, não haverá reexame necessário. E se a parcela da sucumbência da Fazenda Pública puder ser tipificada numa das hipóteses dos incisos do art. 496? Com considerável boa vontade pode-se interpretar que a apelação mencionada no dispositivo legal é da Fazenda Pública, só havendo reexame necessário na hipótese de ela não interpor o recurso. Contudo, ainda assim o dispositivo é problemático porque historicamente a apelação da Fazenda Pública nunca impediu o reexame necessário por duas razões: o recurso pode ser parcial, enquanto o reexame necessário é sempre total, e o recurso pode não ser admitido por vicio formal, enquanto o reexame não corre esse risco, sendo sempre julgado pelo tribunal de segundo grau" (NEVES, Daniel Amorim Assumpção. Novo Código de Processo Civil: Lei 13.015/2015. São Paulo: Método, 2015. p. 523-524). 
necessário reexame de toda a matéria pelo tribunal ad quem, ou, optando por apresentar apelação, preocupar-se em elaborar recurso amplo, abarcando todos os capítulos da sentença que entender passíveis de alteração.

Outra situação interessante é o caso de apelação apresentada pelo procurador que não é conhecida pelo tribunal por falta de cumprimento dos pressupostos de admissibilidade recursal. Nessa hipótese, ainda que o não cumprimento tenha se dado por pressupostos intrínsecos, ${ }^{12}$ para fins de remessa necessária estaríamos diante de uma situação equivalente à não interposição, tendo em vista ser do interesse da sociedade, ao menos na visão do legislador, que aquela sentença contrária à Fazenda Pública, uma vez superados os limites impostos pelos $\iint 3^{\circ}$ e $4^{\circ}$ do citado art. 496, seja reapreciada pela segunda instância.

Por seu turno, compondo a estratégia processual a ser adotada pelo procurador em cada caso, cabe a este também mensurar a oportunidade de interposição de apelação tendo em vista o previsto no $\int 11$ do art. 85 do NCPC. Isso porque, conforme esse dispositivo, "o tribunal, ao julgar recurso, majorará os honorários fixados anteriormente levando em conta o trabalho adicional realizado em grau recursal". ${ }^{13}$ Entretanto, a doutrina é uníssona em considerar o reexame necessário mera condição de eficácia da sentença proferida contra a Fazenda Pública, portanto não tendo natureza de recurso.

Assim, caso o processo seja remetido à segunda instância somente para julgamento de reexame necessário, não se vislumbra a possibilidade de aumento dos honorários então definidos em sentença sujeita ao obrigatório duplo grau de jurisdição, seja pela interpretação literal daquele comando normativo, seja pela impossibilidade de reforma daquela de modo a piorar a condenação a que a Fazenda Pública já está sujeita. ${ }^{14}$ Nessa perspectiva, além dos já explorados limites quantitativos e qualitativos à aplicação do instituto da remessa necessária, bem como

12 MOREIRA, José Carlos Barbosa. Comentários ao Código de Processo Civil. Rio de Janeiro: Forense, 2003. v. 5.

13 "Art. 85. A sentença condenará o vencido a pagar honorários ao advogado do vencedor. [...] $§ 11$ O tribunal, ao julgar recurso, majorará os honorários fixados anteriormente levando em conta o trabalho adicional realizado em grau recursal, observando, conforme o caso, o disposto nos $\S \S 2^{\circ}$ a $6^{\circ}$, sendo vedado ao tribunal, no cômputo geral da fixação de honorários devidos ao advogado do vencedor, ultrapassar os respectivos limites estabelecidos nos $\S \S 2^{\circ}$ e $3^{\circ}$ para a fase de conhecimento."

14 Súmula n. 45 do STJ: "No reexame necessário, é defeso, ao Tribunal, agravar a condenação imposta à Fazenda Pública”. 
em função do risco de preclusão em caso de recurso voluntário parcial, caberá ao representante em juízo do ente público considerar a oportunidade de interposição de apelação também sob a dimensão da possibilidade de agravamento da condenação da Fazenda Pública.

Por fim, como bem alertado por Rogério Mollica, ${ }^{15}$

não sendo caso de dispensa e sendo certo que o processo deverá ser submetido ao Reexame Necessário, é possível que o juiz leve tal obrigatoriedade em conta na fixação dos honorários advocatícios e não os fixe na alíquota mínima de cada faixa de honorários, já que se sabe de antemão que o processo não poderá se encerrar em primeira instância.

\section{A EXCEÇÃO DE PRÉ-EXECUTIVIDADE JULGADA PROCEDENTE EM SEDE DE EXECUÇÃO FISCAL E A REMESSA NECESSÁRIA}

Nos termos do art. $3^{\circ}$ da Lei n. 6.830/1980 (Lei de Execuções Fiscais - LEF), em reprodução ao que dispõe o art. 204 do Código Tributário Nacional (CTN), "a dívida ativa regularmente inscrita goza da presunção de certeza e liquidez". Em outras palavras, quis o legislador garantir que o débito de natureza tributária, uma vez inscrito em dívida ativa, pressupõe: (i) quanto à sua certeza, existência regular com origem, desenvolvimento e perfazimento conhecidos, natureza determinada e fundamento legal induvidoso; e (ii) quanto à sua liquidez, que o título executivo ostenta elementos que permitam, a qualquer tempo, o cálculo do montante integral do débito, incluindo principal, juros, multa e demais encargos.

Destarte, nos termos do parágrafo único do mesmo art. $3^{\circ}$ da LEF e/ou do art. 204 do CTN, a presunção de liquidez e certeza da dívida ativa é "relativa e pode ser ilidida por prova inequívoca, a cargo do executado ou de terceiro, a quem aproveite". No ensinamento de José Jayme de Macêdo Oliveira, ${ }^{16}$

15 MOLLICA, Rogério. A remessa necessária e o Novo Código de Processo Civil. In: DIDIER JR., Fredie et al. (Coord.). Processo nos tribunais e meios de impugnação às decisões judiciais. São Paulo: Juspodivm, 2016. p. 107.

OLIVEIRA, José Jayme Macêdo. Código Tributário Nacional: comentários, doutrina e jurisprudência. 5. ed. São Paulo: Saraiva, 2010. p. 574. 
A inscrição outorga à dívida ativa o privilégio de constituir prova pré-constituída, o que significa que a lei inverte o ônus da prova do processo judicial, onde a regra geral imperante é no sentido de que a prova sempre incumbe a quem alega o fato. Assim, no executivo fiscal, ao invés de o Estado provar que tem o direito a seu favor, cabe ao contribuinte, caso não concorde com a exigência, provar que não deve, que já pagou, ou que deve menos do que the é reclamado, sob pena de ser totalmente válida a cobrança.

Nesse cenário, caberia ao executado, uma vez invocando causas extintivas, impeditivas ou modificativas do direito encerrado no título executivo de natureza fiscal que deu ensejo à execução que lhe é movida pela Fazenda Pública competente, apresentar defesa nos moldes do art. $16 \mathrm{da} \mathrm{LEF},{ }^{17}$ isto é, embargos à execução fiscal, impondo-se como requisito a garantia do respectivo juízo.

Ocorre que, dentre as possíveis alegações do executado em sede de embargos à execução fiscal, há aquelas que, por representarem interesse geral da sociedade em vistas à preservação da ordem pública, podem ou devem ser conhecidas de ofício pelo juízo competente. Nessa seara, citamos todo e qualquer vício formal ou material do título executivo objeto da execução fiscal, os quais, uma vez inegavelmente identificados, eivam-no de nulidade. Para essas hipóteses, visando evitar a continuidade ou a efetiva perturbação da ordem pública, foi construída na doutrina uma modalidade de defesa em sede de execução pela qual o executado poderia, invocando justamente a nulidade ou anulabilidade do título ensejador de cobrança, arguir quanto às causas extintivas, impeditivas ou modificativas do direito nele encerrado sem a necessidade de garantia prévia do juízo. E, para essa modalidade de defesa, foi atribuída a denominação exceção de pré-executividade.

Após sua aceitação generalizada pela jurisprudência pátria, o STJ, no julgamento do Recurso Especial (REsp) n. 1.110.925/SP, ${ }^{18}$ representativo da controvérsia e submetido ao regime previsto no art. 543-C CPC/73, pacificou o entendimento segundo o qual, em sede de execução fiscal, a exceção de pré-executividade é cabível nas situações em que observados concomitantemente dois pressupostos, quais sejam: (i) a matéria suscitada é passível de conhecimento de ofício pelo juiz e (ii) não é necessária dilação probatória. Portanto, depreende-se que a decisão que

17 “Art. 16. O executado oferecerá embargos, no prazo de 30 (trinta) dias [...] § $1^{\circ}$ Não são admissíveis embargos do executado antes de garantida a execução" (grifo nosso). 
acolhe a exceção de pré-executividade, sendo meritória e não impugnada pela procuradoria competente, faz coisa julgada.

Sob esse prisma, se poderia indagar quanto à aplicação da remessa necessária nesses casos, ainda que a situação não esteja expressamente prevista no citado art. 496 do NCPC. A resposta é afirmativa, pois a decisão que dá provimento à exceção de pré-executividade, uma vez que lhe aprecie o mérito, não só tem natureza de sentença, sendo inclusive passível de apelação e, portanto, estando abarcada pelos ditames do inciso I daquele dispositivo de lei, como seus efeitos coincidem com aqueles próprios dos embargos à execução, fazendo-lhes as vezes na essência e, nesse caso, subsumindo-se à hipótese do inciso II daquele mesmo artigo do NCPC.

\section{O JULGAMENTO PARCIAL E ANTECIPADO DE MÉRITO E A REMESSA NECESSÁRIA}

Nos termos do art. 356 do NCPC:

Art. 356. O juiz decidirá parcialmente o mérito quando um ou mais dos pedidos formulados ou parcela deles:

I - mostrar-se incontroverso;

II - estiver em condições de imediato julgamento, nos termos do art. 355.

Aqui, parece evidente tratar-se de situação em que a causa é solucionada mediante cognição exauriente, portanto apta a fazer coisa julgada nos termos do art. 502 do NCPC, entretanto, instrumentalizada por decisão interlocutória. Isso porque os $\Omega \int 1^{\circ}$ e $5^{\circ}$ do citado art. 356 esclarecem a natureza jurídica dessa decisão na hipótese, haja vista tratá-la justamente como "decisão", ${ }^{19}$ então sujeita à impugnação mediante agravo de instrumento. ${ }^{20}$

Examinada a natureza da decisão proferida nos termos do art. 356, cabe investigar se essa, uma vez apta a fazer coisa julgada, estaria sujeita ao instituto da remessa necessária. É importante destacar, a priori, que o caput do art. 496 do NCPC refere-se unicamente à "sentença", do que se pode concluir que o instituto

19 "Art. 356. [...] $1^{\circ}$ A decisão que julgar parcialmente o mérito poderá reconhecer a existência de obrigação líquida ou iliquida."

20 "Art. 356. [...] §5 A decisão proferida com base neste artigo é impugnável por agravo de instrumento." 
da remessa necessária não se aplicaria, portanto, aos casos de julgamento parcial e antecipado de mérito, nos termos do citado art. 356 da novel legis processual. Essa conclusão é corroborada por uma interpretação declarativa restritiva daquele, conforme já vinha sendo adotada pelo STJ ${ }^{21}$ em análise da remessa necessária ainda sob a égide do art. 475 do CPC/73, em corolário ao método lógico-racional de hermenêutica jurídica, justificada, nesse caso, pela excepcionalidade da prerrogativa em prol da Fazenda Pública.

Com mais razão, atente-se para o fato de que a decisão interlocutória de mérito do citado art. 356 do NCPC parece encerrar regime especial de eficácia, pois gozaria de "privilégios" comparativamente à própria sentença final, já que é desde logo eficaz, ${ }^{22}$ bem como “dispensa' caução para a execução provisória”, 23 o que, pelo

21 "AGRAVO REGIMENTAL EM RECURSO ESPECIAL. PROCESSUAL CIVIL. VIOLAÇÃO DO ARTIGO 535 DO CÓDIGO DE PROCESSO CIVIL. REEXAME NECESSÁRIO. OMISSÃO. INEXISTÊNCIA. 1. "A jurisprudência deste Superior Tribunal de Justiça consolidou já entendimento segundo o qual deve a parte vincular a interposição do recurso especial à violação do artigo 535 do Código de Processo Civil, quando, mesmo após a oposição de embargos declaratórios, o tribunal a quo persiste em não decidir questões que the foram submetidas a julgamento, por força do princípio tantum devolutum quantum appellatum ou, ainda, quando persista desconhecendo obscuridade ou contradição arguidas como existentes no decisum." (AgRgREsp 353.697/SP, da minha Relatoria, in DJ 19/12/2002). 2. Em não tendo sido suscitada a matéria no recurso de apelação, não há falar em violação do artigo 535 do Código de Processo Civil, por não haver omissão a ser suprida. 3. O duplo grau de jurisdição obrigatório, como na boa doutrina, não é recurso, tem estatuto processual próprio e em nada se relaciona com o recurso voluntário, daí por que não se the aplicam as normas referentes à apelação, limitando-se a transferir a reapreciação da matéria suscitada, discutida e decidida na sentença, ressalvadas as questões de ordem pública, de conhecimento e julgamento obrigatórios, mesmo que não tenham sido suscitadas, em virtude, é verdade, da remessa necessária, mas por não the ser estranho o efeito translativo, não comportando tais questões a preclusão. 4. As normas de reexame necessário, por óbvio, pela sua afinidade com o autoritarismo, são de direito estrito e devem ser interpretadas restritivamente, em obséquio dos direitos fundamentais, constitucionalmente assegurados, até porque, ao menor desaviso, submeter-se-á o processo a tempos sociais prescritivos ou, o que não é menos grave, a aprofundamentos intoleráveis de privilégios, denegatórios do direito à tutela jurisdicional. 5 . Agravo regimental improvido" (STJ, Embargos de Declaração no AgRg no REsp n. 353.697, Min. Rel. Hamilton Carvalhido, julgamento em: 3 fev. 2004, DJ: 16 fev. 2004).

22 Conforme anteriormente indicado, essa decisão interlocutória é impugnável por intermédio de Agravo de Instrumento, sendo que, nos termos do art. 995 do NCPC, este não tem efeito suspensivo automático, ao passo que, nos termos do art. 1.012 do NCPC, a apelação, meio pelo qual se impugna uma sentença, o tem.

23 TALAMINI, Eduardo. Reexame necessário: hipótese de cabimento no novo CPC/2015. 15 mar. 2016. Disponivel em: <http://www.migalhas.com.br/dePeso/16,Ml235769,31047-Reexame+necessario+hipoteses+de+cabimento+no+CPC15>. Acesso em: 25 out. 2018. 
método sistemático ou orgânico de hermenêutica jurídica, embasaria, no contexto, a não aplicação da remessa necessária à espécie. ${ }^{24}$

É importante destacar em tempo que, no caso específico do processo tributário, o objeto litigioso, via de regra, versa sobre questão cuja prova documental, exibida com a petição inicial, é suficiente para a certificação do fato constitutivo do direito deduzido pelo contribuinte, assim, a situação objeto do art. 356 é jurídica e materialmente provável. Com efeito, podemos imaginar inúmeros casos em que o juízo competente estará compelido a julgar parcial e antecipadamente tema incontroverso, conforme aduzido por irrefutável prova documental apresentada pelo contribuinte, não sendo lógico sujeitar-se essa decisão interlocutória ao duplo grau de jurisdição obrigatório.

A título de exemplo, cite-se ação ajuizada pelo contribuinte mediante a qual se combata a constituição e a inscrição em dívida ativa de créditos tributários lançados por autoridade fiscal em seu nome, ficando comprovado que um desses créditos tributários já se encontra extinto, uma vez que devidamente pago. Nessa hipótese, seria possível imaginar que o procurador competente não ofereceria impugnação à decisão que venha a julgar procedente o pedido de anulação e cancelamento de inscrição daquele crédito já extinto, não sendo razoável, portanto, remetê-la ao tribunal para sua reapreciação.

\section{TUTELA ANTECIPADA ANTECEDENTE E REMESSA NECESSÁRIA}

Nos termos do art. 304 do NCPC, a decisão que conceda tutela antecipada antecedente pode estabilizar-se quando não for objeto de recurso. Nesse caso, nos

24 Contrapõe-se a esse entendimento Leonardo José Carneiro da Cunha, nos seguintes termos: "É possivel que o juiz decida o mérito contra a Fazenda Pública por meio de uma decisão interlocutória. Com efeito, o juiz pode decidir parcialmente o mérito, numa das hipóteses previstas no art. 356. Tal pronunciamento, por não extinguir o processo, é uma decisão interlocutória, que pode já acarretar uma execução imediata, independentemente de caução (CPC, art. $356, \S^{\circ}$ ). Conquanto seja uma decisão interlocutória, há resolução parcial do mérito, apta a formar coisa julgada material. Mesmo não sendo sentença, estará sujeita à remessa necessária. Isso porque a remessa necessária relaciona-se com as decisões de mérito proferidas contra a Fazenda Pública; a coisa julgada material somente pode ser produzida se houver remessa necessária. Se houve decisão de mérito contra o Poder Público, é preciso que haja o seu reexame pelo tribunal respectivo; é preciso, enfim, que haja remessa necessária. Significa então, que há remessa necessária de sentença, bem corno da decisão interlocutória que resolve parcialmente o mérito" (CUNHA, Leonardo José Carneiro da. In: WAMBIER, Teresa Arruda Alvim et al. (Coord.). Breves comentários ao Novo Código de Processo Civil. São Paulo: Revista dos Tribunais, 2015. p. 1256-1257). 
termos do $\int 6^{\circ}$ do mesmo comando normativo, essa decisão não fará coisa julgada, mas produzirá efeitos por tempo indeterminado.

Aqui, da mesma forma discutida quanto ao julgamento antecipado ou parcial de mérito do art. 356 do NCPC, se poderia indagar se essa decisão que deferiu a tutela antecipada se submeteria à remessa necessária, uma vez que não impugnada. Aplicando-se o mesmo método interpretativo restritivo alhures, se concluiria pela negativa de aplicação do instituto nesse caso.

Nesse ponto, reitera-se o argumento utilizado pelo STJ desde 2004, quando a remessa necessária ainda era regulada pelo art. 475 do CPC/73, qual seja: "as normas de reexame necessário, pela sua afinidade com o autoritarismo, são de direito estrito e devem ser interpretadas restritivamente". Isso significa que, quando o legislador se utilizou da expressão "sentença" no caput do art. 496 do NCPC, dentre os atos que compõem o curso regular de um processo, quis restringir a aplicação do instituto unicamente a esse momento.

A corroborar essa conclusão, repise-se que a doutrina e a jurisprudência, em uníssono, entendem que a remessa necessária tem natureza de mera condição de eficácia de sentença proferida contra a Fazenda Pública. Ou seja, sua função é garantir o reexame, por parte da segunda instância, da matéria objeto de decisão de mérito da primeira, tendo como efeito imediato protelar a formação de coisa julgada.

Ora, se uma decisão interlocutória não tem o condão de fazer coisa julgada, como é o caso daquela que defira pedido de antecipação de tutela em regime antecedente, com mais razão não se pode imaginar razoável submetê-la a um duplo grau de jurisdição obrigatório. Isso porque, nesse caso, não se tem solução do conflito mediante cognição exauriente, mas tão somente a estabilização de resultados práticos, portanto ainda passíveis de revisão.

Outrossim, em complementação a esse raciocínio e valendo-se do método sistemático ou orgânico de hermenêutica jurídica, há de se ponderar que de um ponto de vista topográfico o art. 496 foi não sem razão inserido na nova codificação processual na terceira seção do capítulo XIII, "Da sentença e coisa julgada", logo após a seção que trata "Dos elementos e dos efeitos da sentença".

Por fim, especificamente no caso do processo tributário, em enfoque meramente prático e corroborando os argumentos anteriores em prol da inaplicabilidade da remessa necessária na hipótese, podemos imaginar a situação em que um contribuinte com dificuldades de obtenção imediata de documentação capaz de instruir petição inicial pretenda requerer o reconhecimento da inexigibilidade de créditos tributários, de modo que esses não sejam objeto de execução fiscal, 
bem como não sejam óbice à renovação de certidão de regularidade fiscal nem impliquem na sua inscrição em cadastro de inadimplentes pela autoridade fazendária competente, uma vez que o auto de infração pelo qual foram lançados e finalmente constituídos esteja, a toda evidência, eivado de nulidade. Pelas próprias natureza e urgência de tal situação, não parece sustentável condicionar-se a eficácia da decisão que defira pedido nesse sentido à apreciação da matéria pelo tribunal ad quem.

\section{CONSIDERAÇÕES FINAIS}

A despeito de críticas ao instituto por parte dos doutrinadores, a remessa necessária foi mantida no NCPC. Entretanto, andou bem o legislador em ao menos limitar sua aplicação conforme novos critérios quantitativos e qualitativos, em ambos os casos mais extensos frente àqueles previstos no artigo que a regulava no $\mathrm{CPC} / 73$.

Por oportuno, destaque-se que a redação do art. 496 pode ser objeto de futuros debates doutrinários e até jurisprudenciais, seja por omissão, seja por interpretações dissonantes quanto ao alcance das expressões ali empregadas.

Ainda assim, por tratar-se de evidente mecanismo de exceção, bem como em respaldo de posicionamento consolidado de tribunais superiores, pode-se afirmar que o instituto deva ser aplicado da forma mais restritiva possível, de modo a evitar conferir-se aos entes públicos privilégio processual injustificado. 